Published in final edited form as:

Eval Program Plann. 2015 June ; 50: 56-62. doi:10.1016/j.evalprogplan.2015.01.009.

\title{
Estimating Development Cost of an Interactive Website Based Cancer Screening Promotion Program
}

\author{
David R. Lairson, PhD, \\ Department of Management, Policy and Community Health, School of Public Health, University of \\ Texas Health Science Center at Houston 1200 Herman Pressler Street, RAS E307 Houston, TX \\ 77030
}

\section{Tong Han Chung, MPH,}

Department of Management, Policy and Community Health, School of Public Health, University of Texas Health Science Center at Houston 1200 Herman Pressler Street, RAS E331 Houston, TX 77030

Lisa G. Smith, MS, MCHES, CCRP,

Department of Physiology and Health Science, Ball State University CL 326F Muncie, IN 47306

Jeffrey K. Springston, PhD, and

College of Journalism and Mass Communication University of Georgia Journalism Bldg, Room 201-B Athens, GA 30602

\section{Victoria L. Champion, PhD, RN, FAAN}

School of Nursing, Indiana University 1111 Middle Drive NU340 Indianapolis, IN 46202

\section{Abstract}

Objectives-The aim of this study was to estimate the initial development costs for an innovative talk show format tailored intervention delivered via the interactive web, for increasing cancer screening in women 50 to 75 who were non-adherent to screening guidelines for colorectal cancer and/or breast cancer.

Methods-The cost of the intervention development was estimated from a societal perspective. Micro costing methods plus vendor contract costs were used to estimate cost. Staff logs were used to track personnel time. Non-personnel costs include all additional resources used to produce the intervention.

Results-Development cost of the interactive web based intervention was $\$ .39$ million, of which $77 \%$ was direct cost. About $98 \%$ of the cost was incurred in personnel time cost, contract cost and overhead cost.

(C) 2015 Published by Elsevier Ltd.

(Corresponding author) David R. Lairson, PhD Phone Number: 713-500-9176, Fax: 713-500-9171 david.r.lairson@uth.tmc.edu. Publisher's Disclaimer: This is a PDF file of an unedited manuscript that has been accepted for publication. As a service to our customers we are providing this early version of the manuscript. The manuscript will undergo copyediting, typesetting, and review of the resulting proof before it is published in its final citable form. Please note that during the production process errors may be discovered which could affect the content, and all legal disclaimers that apply to the journal pertain. 
Conclusions-The new web-based disease prevention medium required substantial investment in health promotion and media specialist time. The development cost was primarily driven by the high level of human capital required. The cost of intervention development is important information for assessing and planning future public and private investments in web-based health promotion interventions.

\section{Keywords}

Early Detection of Cancer; Development costs; Colorectal cancer; Breast Cancer

\section{INTRODUCTION}

Colorectal cancer (CRC) and breast cancer (BC) are the second and third most common causes of cancer mortality in the United States, respectively. (Howlader, Noone, \& Krapcho, 2013) In 2014, 136,830 new cases and 50,310 deaths from CRC and 235,030 new cases and 40,430 deaths from BC are expected. (Siegel, Ma, Zou, \& Jemal, 2014) The American Cancer Society, the United Preventive Services Task Force, and National Comprehensive Cancer Network Screening recommend routine screening for both CRC and BC as an effective method for reducing morbidity and mortality. (Bevers et al., 2009; Burt et al., 2010; Calonge et al., 2008; B. Levin et al., 2008; Smith et al., 2003; US Preventive Services Task Force, 2009)

Unfortunately, screening for colorectal cancer and breast cancer is underutilized. The percentage of mammogram use within the past two years was $66.5 \%$ in 2010 and combined colorectal screening with either fecal occult blood testing (FOBT) or endoscopy was $59.1 \%$ in 2010. (American Cancer Society, 2014) Behavioral scientists have identified tailored screening interventions as an effective method of increasing cancer screening. (Sohl \& Moyer, 2007) Miller et al. found that web-based multimedia programs increased CRC screening orders to $30 \%$ compared to $21 \%$ for controls and completion to $19 \%$ compared to $14 \%$ for controls, although these results were not statistically significant. (Miller et al., 2011) Researchers have used computer based interventions for BC education. Green et al. found that counseling session time for genetic testing was significantly reduced with the interactive computer program and Ozanne et al reported that a computerized decision aid significantly increased BC knowledge compared to the control group. (Green et al., 2005; Ozanne, Annis, Adduci, Showstack, \& Esserman, 2007) Percac-Lima et al have shown that a culturally tailored, language-concordant navigator program increased the CRC screening rate to $27 \%$ compared to $12 \%$ in the control group and Fitzgibbon et al. reported that women who participated in a culturally tailored classroom instruction intervention were 3.4 time more likely to do a monthly breast self-exam compared to the control group. (Fitzgibbon, Gapstur, \& Knight, 2004; Percac-Lima et al., 2009)

The purpose of this paper is to report the development costs of an intervention based on theoretical models that have demonstrated efficacy for multiple health behaviors. (Noar, Chabot, \& Zimmerman, 2008; Prochaska, Spring, \& Nigg, 2008) Our intervention moves the education to a modern web-based platform. The promise is that this platform will be more convenient, more interactive, and more powerful than traditional print, telephone, and 
$\mathrm{CD}$ based interventions. We are currently conducting the implementation of the web-based intervention. Future papers will report on the effectiveness and cost-effectiveness of the intervention relative to traditional telephone counseling intervention for increasing the screening rates.

A pressing issue in development of population based screening programs is cost of both the development of the program as well as delivery. Analysts have assessed the costeffectiveness of various screening programs for cancer and other chronic diseases. (Andersen, Urban, Ramsey, \& Briss, 2004; Sequist, Zaslavsky, Marshall, Fletcher, \& Ayanian, 2009) The Centers for Disease Control and Prevention has estimated the startup costs for community based colorectal cancer screening programs. (Tangka et al., 2008) However, there are few studies of development cost of screening promotion programs. Two studies estimated the cost of developing interventions that utilized print based and computer based technology, but did not involve use of the internet. They include a study of development of a computer assisted tailored mail intervention to increase mammography screening among women veterans in the United States that assessed development cost at $\$ 335,000$ in 2010 dollars. (Lairson et al., 2004) Similarly, a study of the development of an office based interactive computer program to increase colorectal cancer screening in Houston, TX was estimated to cost about $\$ 380,000$ in 2010 dollars. (Lairson et al., 2006) Both projects had creative design from doctoral trained behavioral scientists, input from the target population, and university staff. Detailed resource use was tracked prospectively as the interventions went through planning, design, and testing stages.

Developmental program costs differ from implementation or recurring program costs in both the resources required and their relevance to program decision-makers. Development requires a high level of human capital to create and test new interventions to improve health and other aspects of consumer well-being. For example, health promotion intervention development requires expert behavioral scientists, and highly trained media specialists. In contrast, the day to day application of the new program or intervention typically requires much less highly trained and less costly personnel, especially if the intervention is partially automated. (Green et al., 2005; Miller et al., 2011; Ozanne et al., 2007) Development costs are inherently more uncertain than recurring costs because the creative process is less predictable than the projected ongoing costs associated with a defined intervention. Decision-makers benefit from information on development costs even though development costs are only marginally relevant when considering whether to fund an existing new intervention. In deciding whether to invest in development of a program or technology, it is important to have a cost estimate to aid in decisions about new program initiatives. (Claxton $\&$ Sculpher, 2006; M. C. Weinstein et al., 2003) Once an intervention is developed and tested, the developmental cost is considered a "sunk cost" and not considered in the economic evaluation of the intervention of delivery except to inform estimates of the cost of adapting the technology to a given setting.

Scant information is available on the amount and components of the cost for web-based interactive screening promotion programs. The cost methods and data will benefit others who plan to develop similar web-based screening intervention programs for different cancers or cultures. (Ritzwoller, Sukhanova, Gaglio, \& Glasgow, 2009) The study 
complements efforts to specify guidelines for project management, especially in areas related to software development which is more dynamic than traditional project management. (Baars, 2006; Boehm, Abts, \& Chulani, 2000) Project management guidelines cover how to manage the project cost within a budget. Managers are tasked with projecting resource requirements including materials and staff time necessary to accomplish the project. However, these estimates are seldom checked to determine their accuracy and may result in delays if resources are insufficient to achieve project targets. In contrast, we prospectively estimate program development cost. The health education field can learn by building up information from these case studies.

This study estimates the initial development costs of a tailored program delivered via the interactive web based intervention, designed to increase screening in women 50 to 75 who are non-adherent to colorectal cancer screening and/or breast cancer screening. The approved cancer screenings for women are cervical, breast, and colon. Because adherence to cervical cancer screening is high, we focus on increasing both breast and colon. Our primary concern was for women who were not adherent to colon cancer screening and this was a basic eligibility criterion. However, it would be negligent to promote colon cancer screening and not ask the woman if she was current with breast cancer screening. Our intent was to create a program that was more inclusive and more efficient by addressing these two important screening behaviors with one intervention.

\section{METHOD}

\section{Intervention Development Process}

Project team members developed the intervention utilizing a "waterfall" or instructional systems design approach. (Larman \& Basili, 2003) The delivery of messages was formatted to a talk show host program with the focus on breast and colon cancer screening. The interactive web based intervention includes message libraries, tailoring algorithms, and content developed in preliminary studies. The intervention development began by convening all key stakeholders: content experts, head of the Community Advisory Board, and the design team from the University of Georgia. Scientific review and content inventory of existing interactive programs were conducted to inform program formatting. Next, the Community Advisory Board provided feedback on the user interface and navigation information from the users' and stakeholders' perspectives. Information about user characteristics and preferences for the programs, including users' expectations of how the interactive products should work on the web was elicited from community advisors.

Based on the results of the focus group sessions and scientific review, co-investigators developed a content matrix document that incorporated messages based on the theoretical constructs. The document was developed to provide messages specific to information gathered by the participant. For instance, if the participant indicated that they were not at risk for colon cancer because they lacked a family history, a message would be delivered providing information that $75 \%$ of individuals who get colon cancer do not have a family history. The design team used the matrix to identify the number and type of media scenarios to be created. Algorithms were then built to match message content to user input. The interactive programming allows users to receive feedback after each question or short series 
of questions. The program was developed such that messages for colon and breast cancer could be synergistic. If a user was adherent to breast cancer screening but not colon, messages to promote colon cancer screening built on their success in obtaining breast cancer screening. If a woman was non-adherent to both breast and colon cancer screening, messages could be created that simultaneously included both screening behaviors. (Figure 1) The left side of Figure 1 shows the information provided for average risk women, where FOBT is an acceptable screening modality along with colonoscopy. The right hand side of the figure guides high risk women to colonoscopy screening. We employed a quality control strategy using heuristic evaluation that included both the website and design studio team and the investigators. All program links and content were tested several times by the design studio team. Then the program was checked multiple times by the investigators to identify and correct any content and navigation errors, and overall usability issues.

The tailored interactive web-site program was created in Adobe Flash with action script 2, which communicates with a MySQL server via PHP to save user data along with the time spent on the program to the server. Though the program was developed in Adobe Flash, an external Excel file was used to plot the program's interactivity including how user-input dictates paths taken within the program. This enabled creative professionals without programming expertise to develop portions of the programming that would normally be developed exclusively by programmers. See appendix for details of the additional software and hardware that was utilized to produce the interactive web based program.

The academic degrees of the video production development team include: BA and Masters in Computer Science and Masters in Instructional Technology. However, most of the expertise necessary to develop the project was learned "on the job." The three senior developers assigned to this project each have between 10 and 20 years of professional experience developing interactive rich media applications. Expertise include: graphical design, animation, video editing, programming, project management, consulting and quality assurance testing. One junior developer with 3 years of professional experience served as the primary video editor under senior developer direction.

\section{Cost Overview}

The cost of the intervention development is estimated from a societal perspective which considers all costs incurred in developing the intervention, including focus group member volunteer time. (Drummond, Sculpher, Torrance, O'Brien, \& Stoddart, 2005; H. M. Levin, 1983; M. Weinstein, Siegel, Gold, Kamlet, \& Russell, 1996) Societal perspective means "that all costs and all effects should be incorporated no matter who pays the costs or who receives the effects... it means that all types of resources of value to society should be included". (Garrison et al., 2010; M. Weinstein et al., 1996) The cost estimate consists of two main parts. First is the conceptualization, modeling, development, and editing done by the research team. A micro costing method is applied by measuring time and other resource inputs weighted by unit prices. (Frick, 2009) Micro costing, "direct enumeration and costing out of every input consumed", is the most precise method for estimating cost in the area of economic evaluation of health programs. (Drummond et al.; H. M. Levin, 1983; M.

Weinstein et al., 1996) Time logs, payroll data, invoices, and unit costs of material were 
used to itemize, quantify, and value these resources. Indirect costs like utilities, maintenance, and administrative services are calculated as 30 percent of direct costs. This assumed rate was based on a study of cancer screening promotion (Chirikos, Christman, Hunter, \& Roetzheim, 2004) The cost model applies the unit prices for materials and the wage and fringe benefit rates for staff that were paid by the project managers in Indianapolis. The web-site design and media development was provided by Eo-Studios, based in Athens Georgia. This cost was measured by the total paid contract amount for these services. It was not feasible to micro cost the activities at Eo-Studios. We also captured volunteer time costs, consistent with the societal perspective. Estimates include initial development cost only and do not contain life cycle costs such as maintenance, upgrade, and delivery. Cost was calculated using an Excel spread sheet and presented in year 2010 U.S. dollars, adjusting differential timing of costs by the U.S. consumer price index. (U.S. Bureau of Labor Statistics)

\section{Eo-Studios Contract Costs}

Eo-Studios developed and tested the intervention web site. Eo-Studios primarily works with university and non-profit organizations that provide medical and education services. The total contract cost was $\$ 135,000$ for the production of the intervention website which included filming the interaction between the actors in the talk show format, editing, website development, and testing.

\section{Personnel time cost}

Personnel time devoted to intervention development was self-reported. The 10 major categories of activities involved in the development of the tailored internet based intervention are listed in table 1. Investigators, consultants, and research assistants reported their time on the intervention development process, exclusive of time spent in formal meetings, which was tracked by the project director. Time data and wage and benefits per hour were used to determine personnel costs. Time log data was collected in a manual system using a Word document on a biweekly basis from July 2010 to January 2011. An alternative internet based time log website, which was secured with individual id and password, was developed by the University of Texas School of Public Health, Information Technology Services department to collect and track staff work time from February 2011 through the end of the development period. The website was designed to be convenient and easy for staff to report their time on one computer screen. The time format was restricted to 'hour: minute' for each episode of project activity and included built in automatic error checks. The web-based program allowed project administrators to monitor each staffs' time $\log$ for quality control.

Time log data was collected monthly. Reminder emails were distributed every month and additional notices were delivered to staff who missed a report. Personnel were able to access the website at any time to report their time and review their entire time entry record. Corrections to the time log record were permitted. If staff failed to record time for more than three months, the information was referred to the project director for follow-up. Official reminders were periodically sent to remind staff of the importance and need for time reporting. Probable errors in the time log were followed up with the staff for correction. 
Adjusted salary per minute was derived from the salary, fringe benefits, productivity rate, and available work time (Table-2). Personnel cost was calculated with the average minutes per task times the adjusted salary per minute of the individual. Wages and fringe benefits were actual values obtained from administrative records. An $85 \%$ productivity rate was assumed based on a previous community based cancer screening promotion study (Andersen, Hager, Su, \& Urban, 2002) and non-intervention related training, nonintervention related meetings, vacation, and holidays were used to adjust the available work time when calculating the adjusted salary per minute. The adjustments recognize that all time is not spent on the project activities and that personnel do not on average perform at $100 \%$ productivity. If there was any missing time, staff members were asked to estimate the time retrospectively. Volunteer time cost was also collected from the focus group sessions, travel time, and time spent to review the prototype of the website intervention program.

\section{Non-personnel cost}

Non-personnel costs include supplies, travel, postal services, etc. These costs include printing costs, envelopes, paper, and all resources used to produce the intervention. The costs of materials were calculated by itemizing the materials needed for each activity and valued according to actual prices paid.

\section{Overhead cost}

Overhead costs, costs of shared resources such as office space, utilities, and general administration, (Drummond et al.) were calculated by multiplying the total direct cost, the summed personnel cost and non-personnel cost, by a 30\% indirect cost rate to approximate overhead in a research setting. (Chirikos et al., 2004)

\section{Sensitivity Analysis}

Uncertainty in methods was estimated with sensitivity analysis. For the assumption of indirect cost rate, the base case estimate is 30 percent with a range of 30 percent to 40 percent, from the preventive health care literature. (Andersen et al., 2002; Lairson et al., 1991; Lairson et al., 1992) Productivity rate was also estimated with the base case is $85 \%$ with a range of 75-95\%. In addition, by combining these two uncertainties, the best and worst scenario of development cost was calculated.

\section{RESULTS}

The results represent data for the 24 month period of the intervention development phase of the project from June 10. 2010 to May 31. 2012. Table 2 shows the adjusted salary rate ranged from $\$ 0.16$ per minute for graduate research assistant 1 to $\$ 2.81$ per minute for professor 5. The intervention development cost was $\$ 391,589$, of which $77 \%$ was direct cost. Personnel time cost and contract cost comprised 74\% of the cost (Table 3). The 18 persons contributed a total of 1610 hours to intervention development (this is the sum of personnel development time and general meeting time). The professors and research scientists spent 934 hours, the product manager spent 333 hours, and the graduate research assistants, administrative assistant, and post-doctoral fellow spent 313 hours. 
When the overhead is varied, the rage of the development cost was $\$ 391,589$ to $\$ 421,712$. The development cost at $75 \%$ and $95 \%$ productivity rate were $\$ 414,649$ and $\$ 373,384$, respectively. The development cost increased by $14 \%$ or $\$ 54,956$ when the overhead is 0.4 and productivity rate is $75 \%$, whereas the development cost decreased by $4.7 \%$ or $\$ 18,205$ when productivity rate is $95 \%$.

\section{DISCUSSION}

The program was developed with a theoretical approach which combined CRC and BC screening with three arguments: First, similar constructs predict adherence to both screening behaviors, thus allowing developers to combine messaging. (Carlos, Fendrick, Patterson, \& Bernstein, 2005; Hall \& Rossi, 2008). Secondly, combining screening interventions will provide a more efficient and cost effective method of increasing cancer screening in nonadherent women. Third, researchers have argued that covariation does occur with BC and CRC as evidenced by the correlation of these variables. (Noar et al., 2008) Tailored health education/health promotion interventions have shown efficacy for increasing CRC and BC screening and can be a cost-effective means for increasing screening adherence. (Clark et al., 2002; Rakowski et al., 1998; Skinner, Campbell, Rimer, Curry, \& Prochaska, 1999)The screening tests have also been shown to be cost-effective. (Frazier, Colditz, Fuchs, \& Kuntz, 2000; Lansdorp-Vogelaar, Knudsen, \& Brenner, 2011) The purpose of developing a webbased program was to deliver an effective intervention in a more cost-effective manner. Our intervention moves the education to a modern web-based platform. The promise is that this platform will be more convenient, more interactive, and more powerful than traditional print, telephone, and $\mathrm{CD}$ based interventions.

Our detailed accounting of the development of a web based interactive talk show format cancer screening promotion intervention yielded a cost estimate of about $\$ 400,000$. This was a collaboration of University professors, media experts, and graduate students from disparate locations with the base at Indiana University Purdue University, at Indianapolis. The majority of the cost for this cancer screening promotion development was personnel time cost. It required many hours of highly trained individual's time to create an engaging and user friendly means to learn about the importance of breast and colorectal cancer screening and identify a personal path to these services.

One important decision the development team made was to utilize an Atlanta-based professional talent agency to hire the actors used in the program. In past studies the team has used local actors from the community theatre community, and local caregivers. While the professional actors cost considerably more per hour than local community actors ( $\$ 1000$ vs. $\$ 500$ per day) and local caregivers (who usually donated their time), filming time was greatly reduced. It took less than half the shooting time to get acceptable takes. The net result yielded a much more refined finished production for roughly the same cost.

Another lesson learned was that the use of teleprompter was important. Because the algorithm was so complex, the script involved multiple versions with slightly nuanced differences. Even though we used professional actors, they could not memorize the entire script with the specificity needed. Use of teleprompters likely saved many hours of filming. 
The next phase of our research will determine whether this level of investment has paid off in an effective and cost-effective intervention.

Our findings can be compared to previous studies that examined the cost of developing computer assisted interventions for increasing cancer screening. (Lairson et al., 2006; Lairson et al., 2004) However, to our knowledge there are no previous estimates of development costs for web based interactive screening promotion interventions. A prior development cost study assessed the resources required to develop a print-based intervention to increase mammography screening among women veterans in the U.S. (Lairson et al., 2004) Computers were used to analyze behavioral questionnaires and produce tailored letters that addressed the respondents concerns about breast cancer screening. The total estimated cost was $\$ 335,000$ in 2010 U.S. dollars. Another study that used similar cost methods estimated the development cost of a clinic based colorectal cancer screening promotion program. That program utilized computer software run on computers located in the health education department of a large multi-specialty clinic in Houston. Participants were able to interact with the program and receive tailored feedback about options for screening and their concerns about the barriers, risks and benefits of screening. (Lairson et al., 2006) The cost of developing the clinic based program was estimated to be $\$ 380,000$. In those two programs, the percent of cost attributable to personnel was about $67 \%$, which is substantially greater than the current study estimate of $40 \%$. The cost estimates were influenced by the size and diversity of the development teams and the role of contractors for production work. If the bulk of contract costs represent payments to personnel in the current study, the percent of cost attributable to personnel increases to $74 \%$ which is similar to the previous study estimates. Using these few studies as an indicator, it appears that the order of magnitude of development cost is similar across different types of cancer prevention programs using different medium for delivering the interventions, mail, computer, and web.

This cost estimate has some limitations. The results may not generalize to other interventions and locations. For instance, time price for staff may be different in other jurisdictions, due to differences in wage and fringe benefits, and other prices. Also risk management costs were not included in the cost estimation, although the upper bounds of the sensitivity analysis may cover them under the higher indirect cost estimates. However, the method may guide other efforts to assess the initial development costs of other health promotion interventions. Personnel time spent on various activities was self-reported with a manual system and an internet-based system, and staff was reminded frequently of the importance of keeping accurate logs. When time was not reported staff members were asked to estimate their time retrospectively. There would likely be overestimation and/or a recall bias with self-reported monthly collection of development time. These limitations could be reduced with an internet-based time log system which enables staff to report their time immediately after their development tasks regardless of period of regular reminders. Adjustment of unit personnel time cost by the productivity (rate) considers that workers have unproductive time during the work hours, which raises the cost of production per unit of output. We were unable to directly estimate this parameter and therefore $85 \%$ is an assumption based on other studies in the health education/ health promotion literature. (Andersen et al., 2002; Chirikos et al., 2004) 
A substantial investment is required to develop internet based theory driven behavioral interventions for community based screening promotion programs. The development cost is primarily driven by the high level of human capital required, including behavioral scientists for the application of theory and professional actors aided by tele-prompters for delivering complex messages that respond to a variety of questions and concerns that people have about cancer screening. Given budget constraints, development cost estimates are important considerations in private sector and public health care policy and planning decisions regarding new $R \& D$ programs and complement guidelines for project management.

\section{Supplementary Material}

Refer to Web version on PubMed Central for supplementary material.

\section{Acknowledgment}

This research was supported by National Cancer Institute (5R01CA136940-02, PI: Victoria L. Champion). The authors of this article would like to acknowledge the support and contribution of research colleagues. Many thanks also to Derek Drawhorn for producing an internet based time log website.

\section{Biography}

David R. Lairson, PhD is Professor of Health Economics and Co-director of the Center for Health Services Research at the University of Texas Health Science Center at Houston. The major focus of his research is the economic evaluation of health services and programs. He has authored several publications on the economic results of prevention and treatment trials and is co-author of the 4th edition of a text, Evaluating the Healthcare System: Effectiveness, Efficiency, and Equity.

Tong Han Chung, MPH is PhD candidate at School of Public Health, University of Texas Health Science Center at Houston and is working as a graduate assistant. His research interests are the economic evaluation of health service, health cancer disparities, comparative effectiveness analysis, and behavioral economics. His dissertation focuses on the racial disparities in utilization patterns and cost-effectiveness of liver cancer treatment.

Lisa G. Smith, MS, MCHES, CCRP is Primary Departmental Advisor \& Instructor in the Department of Physiology and Health Science at Ball State University, Muncie, Indiana. Lisa has a Master's Degree in Health Science from Ball State University. Her experience as a Health Education Specialist has focused on underserved populations, tobacco control, women's health services, and women's health research. She is a Master Certified Health Education Specialist as well as a Certified Clinical Research Professional.

Jeffrey K. Springston, PhD is Professor and Associate Dean for Research and Graduate Studies, College of Journalism and Mass Communication, University of Georgia, Athens, Georgia. His research interests are health promotion, public relations, and emerging communication technologies.

Victoria L. Champion, PhD, RN, FAAN is Distinguished Professor, Department of Environments for Health; Associate Director of Population Science, IU Simon Cancer 
Center, School of Nursing, Indiana University, Indianapolis, Indiana. Her program of research spans 30 years and is focused on primary and secondary interventions to improve cancer screening.

\section{Reference}

American Cancer Society. Cancer Prevention \& Early Detection Facts \& Figures 2014. American Cancer Society; Atlanta: 2014.

Andersen MR, Hager M, Su C, Urban N. Analysis of the cost-effectiveness of mammography promotion by volunteers in rural communities. Health Educ Behav. 2002; 29(6):755-770. [PubMed: 12456132]

Andersen MR, Urban N, Ramsey S, Briss PA. Examining the cost-effectiveness of cancer screening promotion. Cancer. 2004; 101(5 Suppl):1229-1238. [PubMed: 15316909]

Baars W. Project Management Handbook. The Hague: DANS - Data Archiving and Networked Services. 2006

Bevers TB, Anderson BO, Bonaccio E, Buys S, Daly MB, Dempsey PJ, et al. Breast cancer screening and diagnosis. Journal of the National Comprehensive Cancer Network. 2009; 7(10):1060-1096. [PubMed: 19930975]

Boehm B, Abts C, Chulani S. Software development cost estimation approaches-A survey. Annals of Software Engineering. 2000; 10(1-4):177-205.

Burt RW, Barthel JS, Dunn KB, David DS, Drelichman E, Ford JM, et al. Colorectal cancer screening. Journal of the National Comprehensive Cancer Network. 2010; 8(1):8-61. [PubMed: 20064289]

Calonge N, Petitti DB, DeWitt TG, Dietrich AJ, Gregory KD, Harris R, et al. Screening for colorectal cancer: US Preventive Services Task Force recommendation statement. Annals of internal medicine. 2008; 149(9):627-637. [PubMed: 18838716]

Carlos RC, Fendrick AM, Patterson SK, Bernstein SJ. Associations in breast and colon cancer screening behavior in women. Acad Radiol. 2005; 12(4):451-458. [PubMed: 15831418]

Chirikos TN, Christman LK, Hunter S, Roetzheim RG. Cost-effectiveness of an intervention to increase cancer screening in primary care settings. Preventive medicine. 2004; 39(2):230-238. [PubMed: 15226030]

Clark MA, Rakowski W, Ehrich B, Rimer BK, Velicer WF, Dube CE, et al. The effect of a stagematched and tailored intervention on repeat mammography. Am J Prev Med. 2002; 22(1):1-7. [PubMed: 11777672]

Claxton KP, Sculpher MJ. Using value of information analysis to prioritise health research. Pharmacoeconomics. 2006; 24(11):1055-1068. [PubMed: 17067191]

Drummond, MF.; Sculpher, M.; Torrance, G.; O'Brien, B.; Stoddart, G. Methods for the economic evaluation of health care programmes. Oxford University Press; New York: 2005.

Fitzgibbon ML, Gapstur SM, Knight SJ. Results of Mujeres Felices por ser Saludables: a dietary/breast health randomized clinical trial for Latino women. Ann Behav Med. 2004; 28(2):95-104. [PubMed: 15454356]

Frazier AL, Colditz GA, Fuchs CS, Kuntz KM. Cost-effectiveness of screening for colorectal cancer in the general population. JAMA. 2000; 284(15):1954-1961. [PubMed: 11035892]

Frick KD. Micro-costing quantity data collection methods. Med Care. 2009; 47(7 Suppl 1):S76. [PubMed: 19536026]

Garrison LP, Mansley EC, Abbott TA, Bresnahan BW, Hay JW, Smeeding J. Good Research Practices for Measuring Drug Costs in Cost-Effectiveness Analyses: A Societal Perspective: The ISPOR Drug Cost Task Force Report—Part II. Value in Health. 2010; 13(1):8-13. [PubMed: 19883405]

Green MJ, Peterson SK, Baker MW, Friedman LC, Harper GR, Rubinstein WS, et al. Use of an educational computer program before genetic counseling for breast cancer susceptibility: effects on duration and content of counseling sessions. Genetics in Medicine. 2005; 7(4):221-229. [PubMed: 15834239]

Hall KL, Rossi JS. Meta-analytic examination of the strong and weak principles across 48 health behaviors. Preventive medicine. 2008; 46(3):266-274. [PubMed: 18242667] 
Howlader, N.; Noone, AM.; Krapcho, M.; Garshell, J.; Neyman, N.; Altekruse, SF., et al. SEER Cancer Statistics Review, 1975-2010.[Based on the November 2012 SEER data submission, posted to the SEER web site, April 2013.]. National Cancer Institute; Bethesda, MD: 2013. Available from: http://seer.cancer.gov/csr/1975_2010/. Redacted for blind review Redacted for blind review Redacted for blind review Redacted for blind review [2014 March 30]

Lansdorp-Vogelaar I, Knudsen AB, Brenner H. Cost-effectiveness of colorectal cancer screening. Epidemiol Rev. 2011; 33(1):88-100. [PubMed: 21633092]

Larman C, Basili VR. Iterative and incremental development: A brief history. Computer. 2003; 36(6): $47-56$.

Levin B, Lieberman DA, McFarland B, Smith RA, Brooks D, Andrews KS, et al. Screening and Surveillance for the Early Detection of Colorectal Cancer and Adenomatous Polyps, 2008: A Joint Guideline from the American Cancer Society, the US Multi-Society Task Force on Colorectal Cancer, and the American College of Radiology. CA: a cancer journal for clinicians. 2008; 58(3): 130-160. [PubMed: 18322143]

Levin, HM. Cost-effectiveness: A primer. Sage; Beverly Hills: 1983.

Lairson DR, Newmark GR, Rakowski W, Tiro JA, Vernon SW. Development costs of a computergenerated tailored intervention. Evaluation and Program Planning. 2004; 27:161-169.

Lairson DR, Chang YC, Bettencourt JL, Vernon SW, Greisinger A. Estimating development cost for a tailored interactive computer program to enhance colorectal cancer screening compliance. Journal of the American Medical Informatics Association. 2006; 13:476-484. [PubMed: 16799126]

Lairson DR, Mains DA, Mullen PD, Velez R. Estimating the cost of education and counseling programs. Patient education and counseling. 1991; 18:179-188.

Lairson DR, Pugh JA, Kapadia AS, Lorimor RJ, Jacobson J, Velez R. Cost-effectiveness of alternative methods for diabetic retinopathy screening. Diabetes care. 1992; 15:1369-1377. [PubMed: 1425103]

Miller DP Jr, Spangler JG, Case LD, Goff DC Jr, Singh S, Pignone MP. Effectiveness of a web-based colorectal cancer screening patient decision aid: a randomized controlled trial in a mixed-literacy population. Am J Prev Med. 2011; 40(6):608-615. [PubMed: 21565651]

Noar SM, Chabot M, Zimmerman RS. Applying health behavior theory to multiple behavior change: Considerations and approaches. Preventive medicine. 2008; 46(3):275-280. [PubMed: 17825898]

Ozanne EM, Annis C, Adduci K, Showstack J, Esserman L. Pilot trial of a computerized decision aid for breast cancer prevention. Breast J. 2007; 13(2):147-154. [PubMed: 17319855]

Percac-Lima S, Grant RW, Green AR, Ashburner JM, Gamba G, Oo S, et al. A culturally tailored navigator program for colorectal cancer screening in a community health center: a randomized, controlled trial. J Gen Intern Med. 2009; 24(2):211-217. [PubMed: 19067085]

Prochaska JJ, Spring B, Nigg CR. Multiple health behavior change research: an introduction and overview. Preventive medicine. 2008; 46(3):181-188. [PubMed: 18319098]

Rakowski W, Ehrich B, Goldstein MG, Rimer BK, Pearlman DN, Clark MA, et al. Increasing mammography among women aged $40-74$ by use of a stage-matched, tailored intervention. Preventive medicine. 1998; 27(5):748-756. [PubMed: 9808807]

Ritzwoller DP, Sukhanova A, Gaglio B, Glasgow RE. Costing behavioral interventions: a practical guide to enhance translation. Annals of Behavioral Medicine. 2009; 37(2):218-227. [PubMed: 19291342]

Sequist TD, Zaslavsky AM, Marshall R, Fletcher RH, Ayanian JZ. Patient and physician reminders to promote colorectal cancer screening: a randomized controlled trial. Arch Intern Med. 2009; 169(4):364-371. [PubMed: 19237720]

Siegel R, Ma J, Zou Z, Jemal A. Cancer statistics, 2014. CA Cancer J Clin. 2014; 64(1):9-29. [PubMed: 24399786]

Skinner CS, Campbell MK, Rimer BK, Curry S, Prochaska JO. How effective is tailored print communication? Annals of Behavioral Medicine. 1999; 21(4):290-298. [PubMed: 10721435]

Smith RA, Saslow D, Sawyer KA, Burke W, Costanza ME, Evans W, et al. American Cancer Society guidelines for breast cancer screening: update 2003. CA: a cancer journal for clinicians. 2003; 53(3):141-169. [PubMed: 12809408] 
Sohl SJ, Moyer A. Tailored interventions to promote mammography screening: a meta-analytic review. Prev Med. 2007; 45(4):252-261. [PubMed: 17643481]

Tangka FK, Subramanian S, Bapat B, Seeff LC, DeGroff A, Gardner J, et al. Cost of starting colorectal cancer screening programs: results from five federally funded demonstration programs. Prev Chronic Dis. 2008; 5(2):A47. [PubMed: 18341782]

U.S. Bureau of Labor Statistics. [09/18, 2014] Consumer Price Index. from http://www.bls.gov/cpi/

US Preventive Services Task Force. Screening for breast cancer: US Preventive Services Task Force recommendation statement. Annals of internal medicine. 2009; 151(10):716. [PubMed: 19920272]

Weinstein, M.; Siegel, J.; Gold, M.; Kamlet, M.; Russell, L. Cost-effectiveness in health and medicine. Oxford University; New York: 1996.

Weinstein MC, O'Brien B, Hornberger J, Jackson J, Johannesson M, McCabe C, et al. Principles of Good Practice for Decision Analytic Modeling in Health-Care Evaluation: Report of the ISPOR Task Force on Good Research Practices-Modeling Studies. Value in Health. 2003; 6(1):9-17. [PubMed: 12535234] 


\section{HIGHLIGHTS}

1. Tailored interactive web-based talk show format program to increase cancer screening

2. Estimate of the development costs to be used in ex ante public investment assessments

3. High level personnel time input represents the major cost component. 


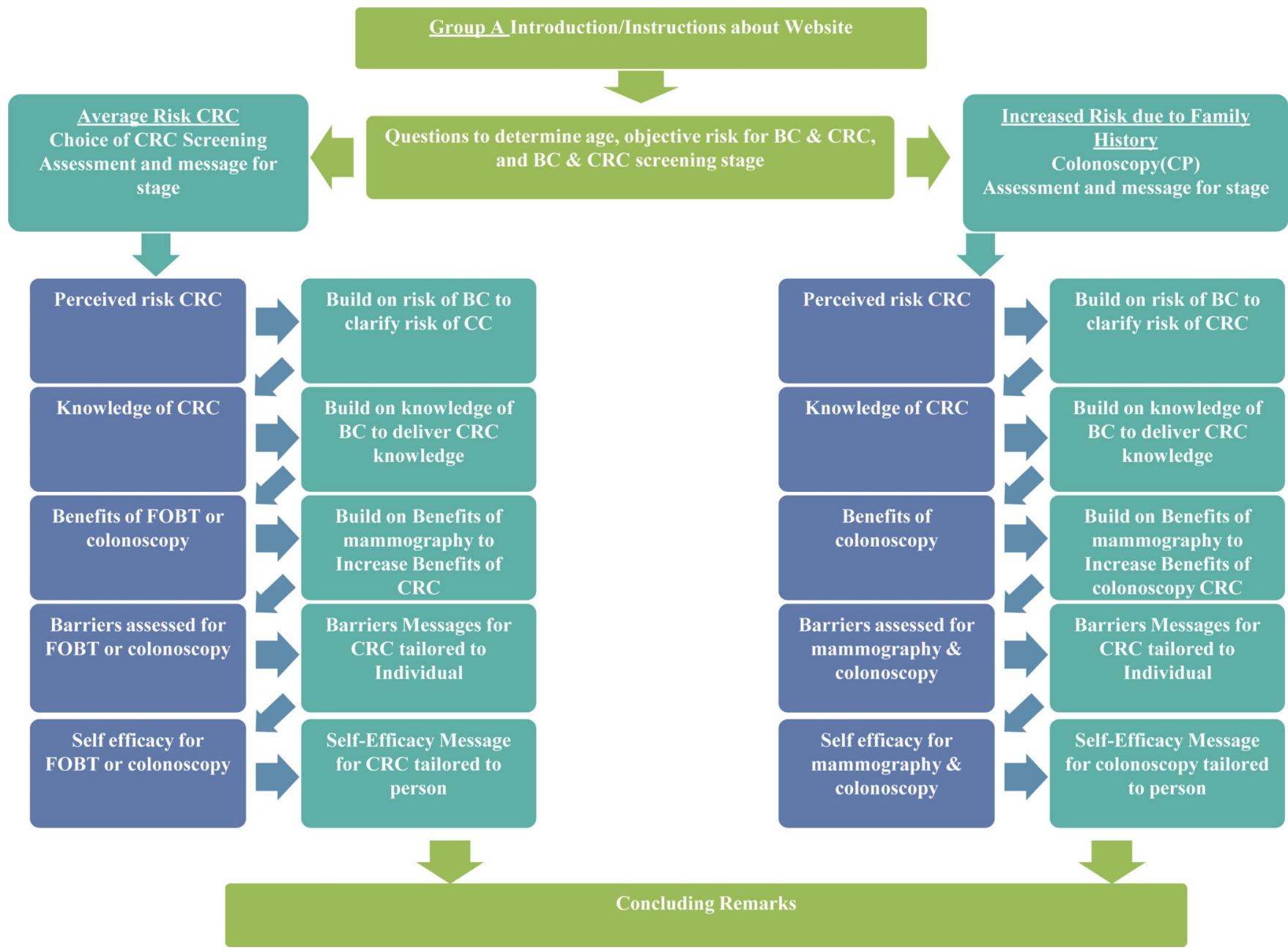

Figure 1.

Flow for Website Content for Individuals Non-adherent to CRC but Adherent to BC Screening 


\section{Table 1}

\section{Major categories of development activities}

\begin{tabular}{c|l}
\hline & Task description \\
\hline 1 & Conduct Scientific Review for Content Inventory \\
\hline 2 & Engage Community Advisory Board to Elicit Feedback on User Interface and Navigation of Existing Programs \\
\hline 3 & Develop the message libraries for intervention groups \\
\hline 4 & Draft the program \\
\hline 5 & Plan Production \\
\hline 6 & Film scenes and record audio \\
\hline 7 & Assemble all elements of the program in draft form \\
\hline 8 & Pre-test tailored intervention (internet program) (40 women 3-5 focus groups) \\
\hline 9 & Edit and Revise program \\
\hline 10 & Other (includes general planning meetings and any other activities that do not fit the 9 specific categories) \\
\hline
\end{tabular}




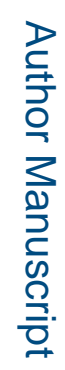

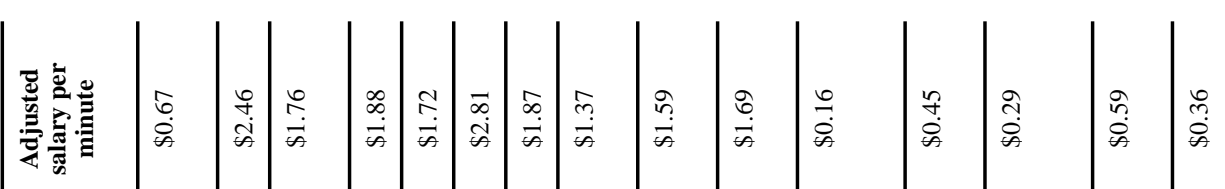

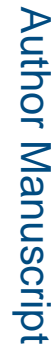

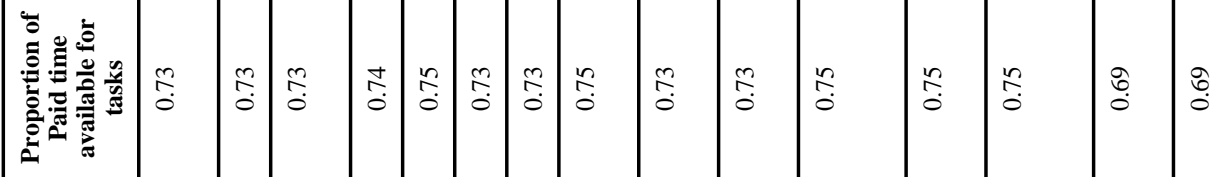

马

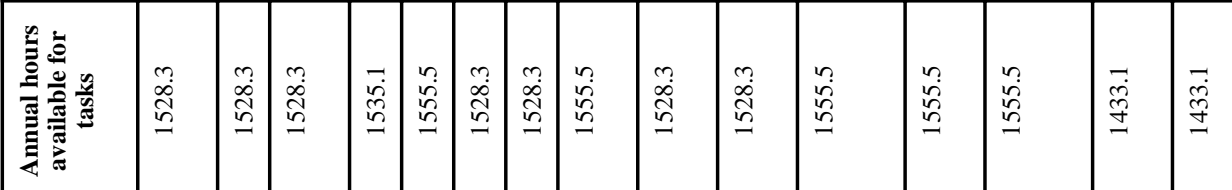

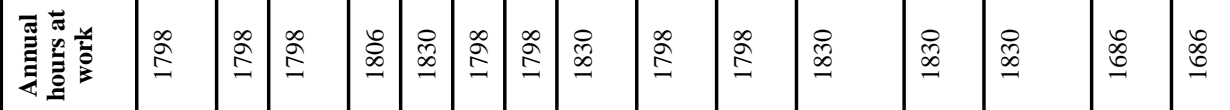

要

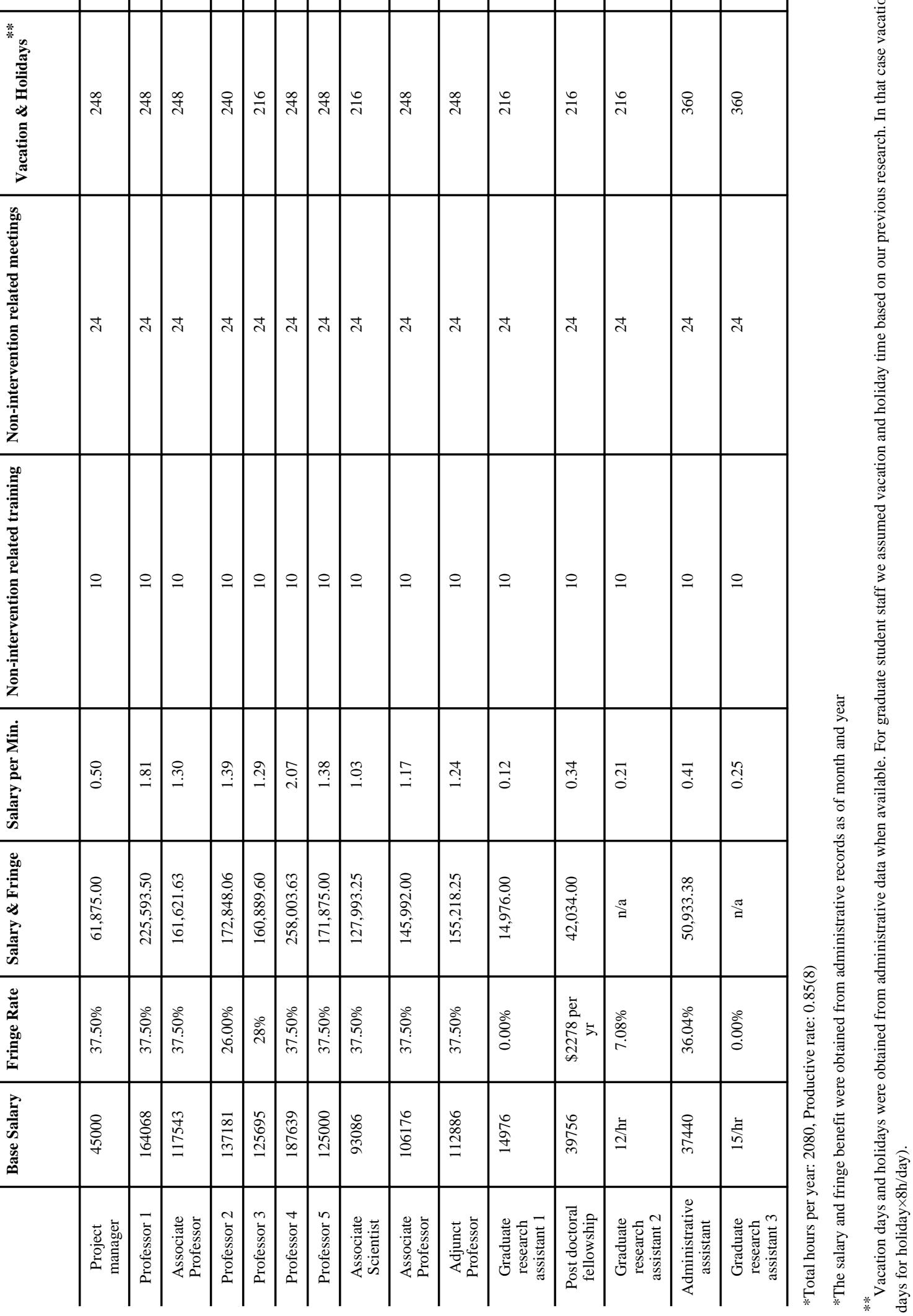


Table 3

Total Intervention Development Costs by Resource Category. (06/10/2010-05/31/2012)

\begin{tabular}{c|c|c}
\hline Resource Category & Cost $\mathbf{\$})$ & Percent of Total Cost (\%) \\
\hline Personnel time & $\$ 153,837$ & $39.29 \%$ \\
\hline Travel & $\$ 9,408$ & $2.40 \%$ \\
\hline Supplies \& equipment & $\$ 2,976$ & $0.76 \%$ \\
\hline Contract cost & $\$ 135,000$ & $34.47 \%$ \\
\hline Overhead & $\$ 90,366$ & $23.08 \%$ \\
\hline Total & $\$ 391,589$ & $100.00 \%$ \\
\hline
\end{tabular}

*Total may not add and percent may not total 100 due to rounding.

Toth ma not add and percent ma not total ho due to rom 
Table 4

Sensitivity Analysis of Overhead Rate and Productivity Rate

\begin{tabular}{c|c}
\hline Variable & Development Cost (\$) \\
\hline Overhead & \\
0.3 & $\$ 391,589$ \\
0.35 & $\$ 406,650$ \\
0.4 & $\$ 421,712$ \\
\hline Productivity rate, \% & \\
75 & $\$ 414,649$ \\
85 & $\$ 391,589$ \\
95 & $\$ 373,384$ \\
\hline The best case & $\$ 373,384$ \\
\hline The worst case & $\$ 446,545$ \\
\hline
\end{tabular}

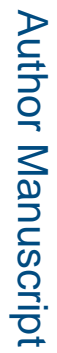

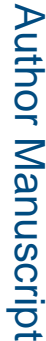

를

Eval Program Plann. Author manuscript; available in PMC 2016 June 01. 